\title{
Vector Modeling for Diagnostics of Future Mathematics Teacher Methodical Training in Higher School
}

\author{
Andrei V. Dorofeev ${ }^{1 *}$, Svetlana E. Chirkina ${ }^{2}$, David V. Gagloev ${ }^{3}$, Tatyana N. Savina 4 \\ ${ }^{1}$ Bashkir State Pedagogical University named after M. Akmullah, Ufa, RUSSIA \\ ${ }^{2}$ Kazan (Volga region) Federal University, Kazan, RUSSIA \\ ${ }^{3}$ Peoples' Friendship University of Russia (RUDN University), Moscow, RUSSIA \\ ${ }^{4}$ National Research Mordovia State University, Saransk, RUSSIA
}

Received 31 March 2018 - Revised 20 July 2018 - Accepted 12 August 2018

\begin{abstract}
The relevance of the present research is defined by the necessity of improvement of methodical training of mathematics teacher in a higher educational institution on the basis of multi-component diagnostics of competencies which represent the multidimensional result of education. Such diagnostics is preferable to be carried out by means of multidimensional vectors which allow not only assessing the educational process from different points of view but also predicting correction of its problematic zones. Purpose of the article is to develop vector method for diagnostics of future mathematics teachers' methodic competencies. The proposed method of vector modeling promotes qualitative and quantitative assessment of the results of methodical training of future mathematics teacher from the point of view of intensity (by means of absolute characteristics) and orientation (in relation to cognitive, activity or value-based components). The article determines such directions of the model of mathematics teacher methodical training as cognitive, social and humanitarian, operational-activity-related, research and methodical. Each of them corresponds to certain competence: information-methodological, social interaction, individual cognitive activity, self-organization and self-management and also system-activityrelated. Criteria for assessment of competencies on the basis of performance of methodical oriented practice tasks and projects were developed.
\end{abstract}

Keywords: vector modeling, competence diagnostics, methodical training, mathematics teaching, mathematics teacher

\section{INTRODUCTION}

The relevance of the issue of teaching staff training is particularly defined by the fact that teacher is the key figure of education. Changes of the orientation, purpose, and content of higher pedagogical education focused on free development, creative initiative, independence and mobility of trainees, especially intensively occur from the end of the XX - the beginning of the XXI century. The content of professional education includes the experience of cognitive activity and emotional-value-based relation to actually studied reality. The objects of scientific cognition are considered as the objects of actual reality. Education, as it was mentioned by Khutorskoy (2002), exists only "when it is developed and till it is developing". Here arises the necessity of detection of methodological basis of the competency-based approach to the development of mathematics teacher methodical training in order to promote the abilities for self-development.

But very often in higher educational institutions the educational process is of conveyor type and individual peculiarities of subjective development of future teachers are not always could be taken into account. The content of pedagogical education supposes obtainment of teaching and professional knowledge and issues of component

(C) 2018 by the authors; licensee Modestum Ltd., UK. This article is an open access article distributed under the terms and conditions of the Creative Commons Attribution License (http://creativecommons.org/licenses/by/4.0/). $\boldsymbol{\nabla}$ an-dor2010@mail.ru (*Correspondence) $\boldsymbol{\nabla}$ sch_61@mail.ru $\boldsymbol{\nabla}$ david.vebber@yandex.ru 


\section{Contribution of this paper to the literature}

- The model for diagnostics of the result of future mathematics teacher methodical training by means of multidimensional vectors, which quantitatively characterize the development of competencies being the part of cognitive, social and humanitarian, operational-activity-related, research and methodical orientation, was developed.

- The peculiarities of vector modeling implementation for complex diagnostics of the results of professional education and process of development of individual educational trajectory of a student while studying elective disciplines of the educational program were detected.

- It has been proved that didactic materials and organizational forms of work developed by authors are focused on the improvement of methodical competencies for professional development of a future mathematics teacher.

composition of pedagogical activity and ways of its implementation often stay unstudied. Teaching and teachingprofessional activity of a student qualitatively differ from the professional activity of a teacher first of all by the subject of activity, the identity of which is implied in the organization of education in higher educational institutions but do not influence the determination of its content, forms and methods of professional training. That is why the program of students actions for familiarization with future activity is not up-to-date.

Main differences between student's activity and teacher's activity are connected with some contradictions existing in the system of professional education: first of all difference between the abstract object of learning and cognitive activity, where dominate texts, semiotic systems, programs of actions, and real object of acquired professional activity, when knowledge is not provided in their pure form, but in the context of working processes and situations; secondly, the difference between the processual side of professional activity of a teacher and static side of learning activity represented by knowledge and algorithms of actions which should be remembered.

The first contradiction is connected with the fact that information in learning activity is its object and in professional activity it transforms into knowledge, i.e. the mean of regulation of such activity. The second contradiction shows that semiotic-symbolic type of learning activity does not allow preparing student for work under conditions of variation of educational programs. Consequently, future mathematics teacher methodical training should be oriented to the development of abilities for innovative and project activity.

Obviously, this brings up some questions: "What kind of mathematics teacher is needed in a modern school? Under which conditions should methodical training of a future mathematics teacher be performed in order to develop such motivated abilities as 1) self-control and activity review; 2) self-sufficiency and mentality originality; 3) ability for critical thinking? On what content it is more appropriate to develop an additional educational program and what types of activity should be used to improve the mathematics teacher methodical training?"

It is well known that professional competencies contain components of different types: actual knowledge, ability to apply knowledge in learning and professional activity, motivation-purpose-orientated aspects. The result of the corresponding type of activity allows assessing the level of competencies development. But similar results could be obtained by subjects also under condition of upgrading different components of competence during activity performance. The process of competence development is represented by the sequential change of actual states, each of which is characterized by the definite composition of components, that is why the change of states depends on current and long-term goals. During competence development, irreversible qualitative transformations of its components take place: achievement by subjects of similar highest points of development is possible even under different initial conditions. These peculiarities show inapplicability to multidimensional object, which the competence is, of the methods of diagnostics based on the isolated assessment of separate parameters of components. It is obvious that development of new approaches, which could become the basis of modeling method, comparable with multidimensional nature of the studied object, is required.

Purpose of the research is to develop the scientific-theoretical basis for diagnostics of future mathematics teacher methodical training in higher school by means of multidimensional vectors.

Reorientation of the educational process of mathematics teacher methodical training from knowledge approach to the competence approach is connected with the settlement of the following issues: 1) to develop the model of mathematics teacher methodical training based on competencies required for efficient organization of mathematical education in school; 2) to determine possibilities for vector modeling for multidimensional diagnostics of the results of future mathematics teacher methodical training in higher school.

Competency-based and student-oriented approaches should be singled out among approaches for settlement of issues connected with development and realization of mathematics teacher methodical training. Competencies represent complex of interconnected semantic orientations, knowledge, skills, abilities, and experience of activity performance, required for realization of personal and socially important productive activity in relation to the objects 
of actual reality. Student-oriented approach for determination of the content of the mathematics teacher methodical training is based on recognition of individuality, originality and inherent value of a person possessing unique subjective experience. Student-oriented studying is realized in the activity supposing cooperation, selfdevelopment of all subjects of educational process and demonstration of their personal qualities.

\section{LITERATURE REVIEW}

Pedagogical reality becomes multidimensional and this requires another language for its description and other approaches for its modeling. Ostapenko (2007) describes multidimensional matrix structure which includes purpose, processual, system-contensive, instrumental, estimative and other invariants. That is why it is impossible to imagine pedagogical studies without application of models of different types. Modeling is the viable method of studying pedagogical objects and the means of finding ways for their transformation (Borovskikh \& Rozov, 2010).

Probabilistic, graphical, algebraic methods, as well as the methods of linear programming, are widely used for the formalization of elements of the educational process (Kiseleva, Timofeeva, \& Bykov, 2013). Determined multidimensional models are used for diagnostics of latent mathematical skills of schoolchildren (Gross, Robitzsch, \& George, 2016). Multidimensional Rasch model serves as the basis for assessing the ability of schoolchildren in acquirability of mathematical methods and development of skills of using mathematical objects (Liu, Wilson, \& Paek, 2008).

Didactic multidimensional instruments are introduced as universal presentative-concept models for multidimensional representation and analysis of knowledge by Shteinberg (2002). They are constructed on the base of the coordinate-matrix framework and solar graphics. A significant role in the methodic training of a teacher is played by didactic analysis (Tkachenko, Shteinberg, \& Manko, 2016). This is connected with the fact that didactic multidimensional instruments perform a lot of functions: 1) programming in non-verbal form of typical operations of knowledge crunching and acquisition, performance of which is required for efficient learning activity (detection of key knowledge elements, rating, establishment of semantic connections, systematization and summarization by means of reformulation); 2) visually suitable shaping of the framework during distribution of information in the plane and its readout (Shteinberg, 2015).

Not professional realities, but information-semiotic models, dominate in studying, that is why pedagogical conditions are required for learning activity transformation into professional. Sequential modeling of professional activity, taking into account objective-technological and social factors, makes a positive impact on cognitive, operational and value-based fields of student's activity. Scientists Kolokolnikova et al. (2015) proposed complex of techniques, ways, methods, and forms for the organization of class and extra-curricular activities aimed at the development of universal competencies of students. Special precedence is granted to those of them, which suppose development of cognitive activity of a future teacher; learn how to analyze, compare, specify, generalize studied material (performed action), organize personal activity, check the correctness and efficiency of its results; form the capability of self-development and self-improvement; prepare for public presentations and teamwork.

The paper (Kirikovich, 2014) represents the didactic model for student self-education. The model is of nonlinear type and is aimed at enhancement of axiological self-determination of a student in terms of designating selfeducation and self-development during the whole life as the way of successful living. The author notes that control of the motion vector of a student in the process of self-education is possible by means of regulating cognitive activity. In terms of organization of future teacher methodic training, one of the main things is the formation of demand for self-development as the essential value of the quick change world. This requires definite conditions (didactic, organizational and informative) thanks to which a student acquires not only result in knowledge, abilities and personal qualities but also skills to develop personal informative models of new knowledge representation.

Modeling of competencies diagnostics by multidimensional vectors has been proved in the following papers (Karaseva \& Dorofeev, 2015; Latypova \& Dorofeev, 2016). Application of three-dimensional vectors for description of the results of mathematical training allows authors clearly characterizing the educational process on three basis: 1) potential capabilities of academic discipline in professionalization of a person; 2) extent of motivation-emotional, cognitive and operational-activity-based components of academic discipline in the development of professional competencies of a student; 3) achievement by a student of education results (Dorofeev \& Latypova, 2015). Vector modeling allows performing the qualitative and quantitative assessment of educational process and predicting correction of its problematic zones.

The entire pedagogical activity consists of two forms: scientific-theoretical and constructive-technological. They form two contours of one and the same process: the first one is focused on cognition of pedagogical activity and the second one on the transformation of this activity in the interest of development and education (Asadullin et al., 2016). Modern education is developing in terms of competency-based approach, supposing not only education and development but also self-education and self-development. In the information-oriented society technologies interchange quite faster than generations of people. It is very important for the person to be able to act under 
continuously changing conditions. Successful self-realization in personal, social and professional spheres depends on the ability to plan, analyze, correct activity and develop the individual strategy for each new situation. Foundation of such skills is the capacity for self-education and readiness for self-development (Asadullin \& Vasil'yev, 2012). Consequently, the main result of methodic training is the person, possessing competencies of individual cognitive activity and self-development and who is able on the basis of these competencies to set goals and plan actions for achievement of these goals.

Motivation to approximate education to life and make results of education more efficient have certain effect and content and organization of educational process are developed through competencies in which cognitive and operational-technological components of the result of education are integrated with the system of ethical, value and motivational orientations of a student (Borisenkov, Gukalenko \& Rozov, 2016). Competencies, being generalized modes of action, provide productive performance by students of educational-cognitive and socialprofessional activity (Dorofeev \& Piadina, 2014). Orientation to the development of competencies requires from higher school provision of qualitatively new education, not by means of increasing the volume of academic training, but by means of orientation of academic disciplines to the development of student's abilities for creative search and continuous knowledge acquisition. Organization of methodic training involves project method, the main purpose of which is the self-sufficient settlement by future teachers of professional tasks. Project methodologies also match the system of extended education when teachers find the ways of settling complex issues of organization of mathematical education based on the obtained pedagogical experience.

The result of professional education, formulated in terms of competencies, is multidimensional. Yalalov and Kaiumova (2015) single out integrative multidimensional competencies: mobility (ability to orient in three dimensions: internal, external, virtual); synergy (capability for self-organization); multitasking (ability to settle several separate issues during performance of one task); multifunctionality (ability to perform several obligations at the same time and at high quality level). Competencies aggregate characteristics of different types and, consequently, their diagnostics should be based on the principle of multidimensionality (Dorofeev \& Arslanova, 2017). This means that professional education requires transfer to self-controlling educational technologies and systems of self-education (Nurullin, 2013, 2014).

Forecasting the results of professional training of a future teacher supposes detection of a complex of competencies. Three parts could be singled out in the structure of competencies: 1) motivation-value-based motives, demands, suggestions, and orientation of activity; 2) content-related - system of professional knowledge, skills, and abilities; 3) operational-activity-based -application of skills and abilities in the professional activity. Practice shows that definite component part of competencies is emphasized in higher degree: either cognitive (knowledge and understanding), or activity-based (practical application of knowledge), or value-based (organic coexistence in the social context). We use the abovementioned positions during mathematics teacher methodic training model development.

The core of mathematics teacher methodic training is answers to the following questions: "What is mathematics?", "How to teach mathematics?" and "Why do we need to teach mathematics?" Quality of mathematical education at school depends on the pedagogical position of a teacher and range of his skills. Mathematics is proving and that is why to teach it is systematically stimulate students to find own arguments. A teacher should teach a student to perform proving discussions, that is why during methodic training it is very important to develop student's ability to distinguish proved facts from things which are only intuitively clear. Methodic training of a teacher is to actuate cognitive activity of students and to find efficient methods of students' motivation for studying mathematics (Li \& Shieh, 2016).

Modernization of general education under modern conditions is oriented to the development of student's ability to set personal academic goals, develop ways for their achievement, control and assess personal achievements. Ability to study starts to prevail, that is why both objective and methodic training of a teacher in higher educational institution and system of advanced training and professional retraining should be changed (Borisenkov, Gukalenko, \& Rozov, 2016). Methodical competence of a mathematics teacher includes the ability to develop such universal educational activities of a student, as cognitive (for example, setting and settlement of issues), personal (for example, establishment by students of connections between the purpose of activity and its motive), regulative (for example, planning and control of activity performance) (Khutorskoy, 2002).

Learning activities manifest in the definite educational tasks and settlement of these tasks - this is the main didactic purpose of the process of mathematical disciplines teaching. Methodic issues of teaching the process of solving tasks are studied by means of step-by-step strategies, acting in the capacity of orientation basis for student's actions (Gok, 2014). Characteristics of didactic-mathematical knowledge of teachers are structurally represented in the following paper (Pino-Fan, Assis, \& Castro, 2015).

Engineering issues of educational tasks and development of didactic situations during the organization of mathematics teacher methodic training are considered by Tchoshanov (2011), who singles out in the structure of holistic approach to the process of solving tasks the following actions: 1) preparation of a task: a) studying situation 
and purpose of task preparation; b) development of the task subject matter and search of necessary data; $c$ ) establishment of semantic connections between data; d) formulation of conditions and requirement of the task; e) check of the prepared task; 2) own solution of the task: a) determination and description of the situation; b) structural analysis of the situation; c) determination of possible variants of solution; d) assessment of variant, selection, and realization of the rational solution; e) check of the realized solution; 3) diagnostics of the solution: a) determination of the fact of the incorrect solution; b) determination of faulty action; c) error cause analysis; d) selection, planning and realization of the way of error correction; e) check of the corrected solution.

Such approach is very useful in term of the methodic teaching of a mathematics teacher the methods of organization of joint educational activity together with students. Moreover, it was noted that difficulties in studying mathematics and academic failure of students mainly depend on didactic and objective knowledge of a teacher, his professional competencies and system of pedagogical values (Chang, 2015; Tchoshanov, Lesser, \& Salazar, 2008). Thus, mathematics teacher methodic training in a higher educational institution should be oriented to different directions of future professional activity, that requires the development of the multidimensional model and corresponding methods of competencies diagnostics.

\section{MATERIALS AND METHODS}

\section{Vector Model of Future Mathematics Teacher Methodic Training}

Modeling becomes the leading method for studying issues of diagnostics of methodic competencies of a future mathematics teacher. Multidimensional vectors c (C1, C2, C3), s (S1, S2, S3), o (O1, O2, O3), r (R1, R2, R3), m (M1, M2, M3) correspondingly represent cognitive, socio-humanitarian, operational-activity, research and methodic orientations in mathematics teacher training (see Figure 1). Methodic orientation is the leading one; it reflects details of vectors responsible for cognitive, research, socio-humanitarian and operational-activity orientations.

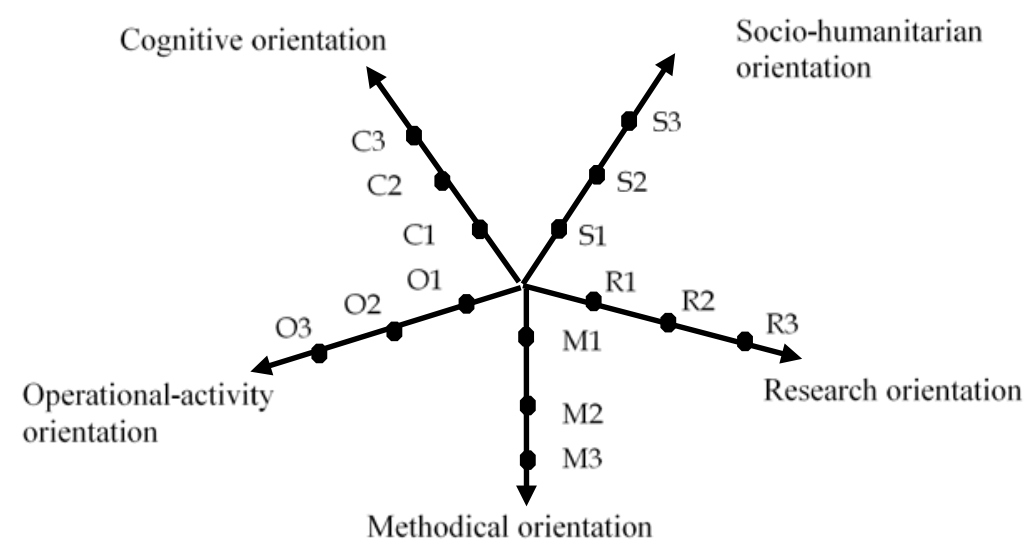

Figure 1. Model of future mathematics teacher methodic training

Let us consider the component composition of vectors in accordance with the determined orientations. Cognitive orientation: $\mathrm{C} 1$ - the ability to work with information of different types; $\mathrm{C} 2$ - the ability to use methods of representation and transformation of information; C3 - the ability to structure and visualize information. Sociohumanitarian orientation: S1- the ability for oral and written expression of thoughts; S2- the ability to hold a constructive dialogue with the audience; S3- the ability for active listening. Operational-activity orientation: O1 the ability to perform analysis of a task, determine conditions and requirements, develop model of a task in the form of schematic record; $\mathrm{O} 2$ - the ability to provide proving arguments during solution of a task on the basis of definitions, theorems, rules, formulas and to develop algorithm of future activity; O3 - the ability to perform check of solutions for compliance with all conditions of the task and to formulate the answer. Research orientation: R1 the ability to formulate the issue, purpose and expressively represent the statement (thesis) of scientific-research activity; R2 - the ability to formulate the theme of future research, indicate the main idea (purpose) of future research, set goals of research; R3 - the ability to perform informational analysis of pedagogical process (notion), process information flows and represent possible forms of project implementation in educational institutions. Methodical orientation: M1 - the ability to set goals, plan and develop educational mathematical activity; M2 - the ability to perform diagnostics or educational activity results; M3 - the ability for self-assessment of the experience of educational process organization and for understanding its impact on student's personality. 


\section{Stages of Vector Model Development}

The process of vector model development consists of the following stages:

1st stage - detection of the set of competencies realized during future mathematics teacher training; planning of educational-methodic materials focused on the development of detected competencies of future mathematics teachers;

2nd stage - performance of the analysis of results of educational and project activity of students for testing diagnostic techniques and organizational forms (for example, carrying out the exam in the form of the creative report based on the results of preparation of projects of methodic orientation to different aspects of mathematical education at school).

\section{First Stage Description}

We generalized experience of work at advanced training courses in the system of extended education of mathematics teachers and personal experience of organization of methodical training for students of pedagogical specialization of the educational institution. Planning the content for mathematics teacher methodic training is based on the logic of scientific knowledge development and its application in the capacity of orientation basis of future professional activity. Knowledge is not a goal in itself, but the means of objective and social actions regulation. From the point of view of content, this process is realized by the three-level organization of educational activity: at orally-verbal (objective) level - mathematical text is processed as the symbolic system and actions are oriented to personified work; at visual-spacial (personally-active) level - social context regulates the creation of images, by means of which systems of psychic formations are generated, providing the possibility of a) obtaining and transforming information about occurring event; b) controlling the process of information processing; c) selectivity of intellectual reflection; at touch-sensitive (creative) level - relations, existing in the system, are identified by actions: "personal-creative dialogue of professional culture" and generation of competencies of future mathematics teacher takes place.

The process of methodic training is based on acquisition, application, and transformation of experience. Threelevel organization of educational activity actualizes development of research skills and abilities to work individually, to apply knowledge in practice and demonstrate the ability to perform logic operations (analysis, synthesis, summarizing and so on) in relation to the studied object.

Development of future teacher personality and generation of his professional competencies are connected with the solution of the following issues: 1) to form scientific-theoretical thinking by means of stimulating motivation, studying logics of mathematical cognition and invariant procedures of intellectual activity; 2) to teach modeling by means of developing the ability of adequate understanding of mathematical object and transformation of its structure; 3) to develop creative activity by means of organization of individual cognitive activity, including the search for non-standard solutions and new ways of activity; 4) developing subject-subject relations for obtaining experience of self-educational activity.

We prepared educational and methodic materials focused on the development of detected competencies of future mathematics teachers. Competencies possess three component parts - cognitive, activity-based and valuebased. We interpret these competencies as the model of actual and predicted results of mathematics teacher methodic training, which, of course, should be amended. Cognitive orientation supposes development of future teachers' abilities to manipulate not only oral and written texts but also figural presentatives represented by formulas, graphs, and tables. In comparison with the linguistic description, the visual percept is more capacious, that is why simultaneous provision of oral text and schematic structure is the sign of creative thinking of a teacher, for whom it is important to actuate the process of understanding of information by students. Text perception is the interpretation of sign system "in two ways" - from text signs to its comprehension and from assigned meaning to coherent content. Text meaning is apprehended at pragmatic, syntactic, semantic and ontological levels. At the pragmatic level occurs the process which changes the psychological state of a person, because reading is work, relaxation, and creativity at the same time. At the syntactic level - vocabulary and symbolic expansion of the subject of activity, development of the ways of correlation and transfer from one sign systems to another. At the semantic level - understanding of generality of text content and detection of connections between separate logical parts. At the ontological level - orientation in materials for processing and regulation of perspective reading. Obtaining experience with educational, scientific, reference and electronic sources of information a future teacher learns how to select material and detect main ideas.

The core of information-methodic competence is the concept of notions, hypotheses, theories and its sensuousfigurative perception. Learning figurative language has a significant influence on professional becoming of a future teacher. Ways and methods of figurative language develop skills of target search of scientific information and detection of essential and external. The creative activity of a student in material systematization is connected with 
the logic-linguistic analysis of mathematical text and construction of graphs that is very important for the development of students' clear understanding of mathematical methods. In order to organize productive work with information by understanding fundamental provisions of science and logic-semantic modeling of educational information, we propose tasks aimed at the development of future teacher abilities to create a figurative interpretation of knowledge for efficient organization of educational process and development of the analogue ability of students for model-figurative representation of information. Let us provide some examples of such tasks:

Practice-oriented task 1: "In the philosophy there are categories (historically developed universals), which could be specified on the basis of logical and mathematical concepts. Illustrate in text, table or graphic form concordance of the following philosophic categories with mathematical objects: ideal - mathematical concept (theory); matter mathematical model (object); motion - function (presentation); quantity - number (value); quality - equivalence relation; shape - formula or geometric figure; content - scope of concept; cause and consequence - sufficient and required condition of the theorem; method - algorithm (way of proving or construction); actual - concrete model; accidental - probability; law - axiom, theorem; system - mathematical structure; action - algebraic operation (transformation)".

Practice-oriented task 2: "For every mathematics teacher answers to the following questions are also very important: "What is quantitative literacy?" and "Which skills and abilities are developed and improved while studying mathematics?" For example, in the framework of international project PISA (Programme for International Student Assessment) were detected criteria of quantitative literacy, which include the following abilities: to define issues, arising in the surrounding reality and successfully solved by means of mathematics; to formulate issues in the mathematical language; to solve issues using mathematical facts and methods; to analyze applied ways of solution; to interpret results taking into account the set issue; to generalize and record solution results. We propose you, using various information sources, to prove the provided criteria of quantitative literacy. Instantiate your arguments with examples".

Development of information-methodic competence, corresponding to the cognitive orientation of mathematics teacher methodic training, is represented by vector $\mathrm{c}(\mathrm{C} 1, \mathrm{C} 2, \mathrm{C} 3)$. Quantitative filling of vector coordinates is in accordance with three-point scale ( 0 points - absence of characteristic; 1 point - partial application of characteristic; 2 points - the entire presence of characteristic) by the following assessment criteria. For the component C1: 1) the ability to work with information of different types is demonstrated; 2 ) sufficient number of information sources are used; 3) applied information sources differ in form and content. For the component C2: 1) the ability for verbal and textual ways of information representation is demonstrated;2) ability of graphical and tabular ways of information representation is demonstrated; 3) methods of information transformation from one type to another are demonstrated. For the component C3: 1) the ability for information structuring is demonstrated; 2) the ability for information visualization is demonstrated; 3 ) information is represented in single structural sequence and is properly coordinated. Each c vector component is within the range from 0 up to 6.

Diagnostics of the competence of social interaction is performed in terms of the socio-humanitarian orientation of mathematics teacher methodic training because complex process of people interaction supposes their social activity. Communication is the condition and at the same time, the result of activity oriented to learning and transformation of the surrounding world. Active listening is the precondition of communication. Development of the ability to listen and constructively interact in terms of conversation, to discuss and make public speaking is one of the main goals of mathematics teacher methodic training. Clearly and precisely express your opinion, provide proving arguments, adequately assess the situation and your own behavior are the indispensable attributes of assertive behavior, orienting a student to self-realization and self-development.

Development of the competence of social interaction is described by vector $\mathbf{s}$ (S1, S2, S3). Let us indicate criteria for competence assessment based on the results of practice-oriented tasks performance and following the abovementioned three-point scale. For the component S1: 1) the ability for clear expression of thoughts in written form is demonstrated; 2) the ability for clear expression of thoughts in oral form is demonstrated;3) readiness for schematic representation of mathematical text. For the component S2: 1) readiness to hold a constructive dialogue with the audience is demonstrated;2) the ability to interact with the group is demonstrated;3) the ability to prove readiness is demonstrated. For the component S3: 1) the ability to understand questions of opponents is demonstrated;2) the ability to give argumentative answers to the raised questions is demonstrated; 3 ) readiness to provide proving statements. Each s vector component is within the range from 0 up to 6.

Competence of individual cognitive activity is realized in terms of the operational-activity-based orientation, characterizing possessing by a student of such skills as planning, predicting, modeling and ability to apply knowledge in practice for the organization of mathematics teaching at school. Mathematics deals with not real objects and processes but their models - approximate description of reality. From elementary numerical models, students gradually proceed to the analysis of more complex qualitative models. Knowledge does not exist in itself - it is called for and collected in the process of education. 
Diagnostics of competence is carried out by the degree of manifestation of action (by completeness, consciousness, and efficiency) in the application of stages of the full effect model and modeling method for mathematical tasks solution. The model consists of stages at which definite operations are realized: 1) informational stage (what should you do?) - perform analysis of the task and determine conditions and requirements; 2) planning (how should you do it?) - construct the model of the task in the form of schematic representation; 3) constructive (what are the means of realization?) - find the way of task solution on the basis of definitions, theorems, rules, and formulas; 4) practical (how to solve the issue?) - perform calculations required for the solution of the task; 5) control (check whether the task solution is correct) - check task solution for compliance with all conditions of the task and its examination: define conditions under which the task is solved; determine the number of solutions in each separate case; determine under which conditions the task has no solution; 6) reflexive -estimating (how to improve?) - formulate the solution of the task and perform cognitive analysis of its solution: why the task is interesting; is there any other ways of its solution; is it possible to generalize the task; what conclusion could be made based on the solution. Obligatory stages of task solution are: analysis, searching the way of solution and solution realization, formulation of the answer. Other stages should be performed in accordance with the requirements of the task itself.

Work with mathematical objects is mainly sign-symbolic activity connected with use and transformation of sign-symbolic means, manipulation of which possesses specific structure and ways of functioning. Difficulties in studying maths are connected with the insufficient development of such skills as 1) decoding of information; 2) identify image with reality; 3 ) detect regularities fixed in models; 4) manipulate models and sign-symbolic means. Operational-activity-based part of mathematical training is realized in sign-symbolic activity oriented to: develop quantitative and spatial representations; learn the main method of mathematics - abstraction; develop the ability to schematize; development of deductive reasoning.

Competence of individual cognitive activity could be diagnosed by acquiring stages of full effect model during the preparation of text story tasks solution. Let us provide an example of such task: "A motorboat and a raft simultaneously left the waterway station A to the waterway station B downstream the river. After reaching the waterway station $B$, the motorboat turned back and met the raft at the distance $A B$ from the station $B$. Find velocity ratio of the motorboat downstream and upstream the river".

Operational-activity orientation is characterized by vector o $(\mathrm{O} 1, \mathrm{O} 2, \mathrm{O} 3)$. Criteria for assessing competence based on the results of text story task are the following. For the component O1: 1) the ability to perform analysis of a task, determine conditions and requirements is demonstrated; 2) the ability to construct model (scheme) of a task, meeting the criteria of conditions adequacy and constructive visualization, is demonstrated. For the component $\mathrm{O} 2$ : 1) the ability to provide proving arguments during solution of a task on the basis of definitions, theorems, rules, formulas statements based on definitions, theorems, rules, and formulas is demonstrated; 2) the ability to develop algorithm of future activity is demonstrated. For the component O3: 1) the ability to provide the correct representation of task solution is demonstrated; 2) the ability to check task solution for compliance with all conditions of the task and ability to formulate the answer are demonstrated.

Assessment is made from the above mentioned three-point scale. Each o vector component is within the range from 0 up to 4 . Operational-activity orientation is connected with sign-symbolic activity and performs the following functions of methodic training: illustrative - determines systematicity of knowledge and operational adequacy of mathematical knowledge acquisition creating external supports for internal mental activity; didactic - supposes goals for cognitive visualization of knowledge and understanding the essence of objects; developing - contributes to the improvement of memory and spatial thinking by means of analysis, syntheses, concretization, and generalization; heuristic - organizes educational activity on the principles of variation, self-sufficiency, and criticality, creating situations of "intelligent difficulty", when incomplete information about the constructed model supposes the search for errors.

Competence of self-organization and self-control is projected to the vector $\mathbf{r}(\mathrm{R} 1, \mathrm{R} 2, \mathrm{R} 3)$ of research orientation. It is based on reflection as a sensuously experienced process of understanding by the subject of his own activity. Reflection is performed in two directions: ontological - connected with the content of objective knowledge and psychological - connected with fixation and assessment of own state during performance of some actions. Diagnostics of the competence is performed on the basis of the results of execution of methodic projects, which were realized by future teachers while solving certain pedagogical situations. Let us provide suggested situations in terms of the discipline "Informatization of education" for students studying in specialty "Pedagogical education", major - "Mathematics and computer science":

Situation 1. Director of the lyceum asked you to speak at the methodic seminar on the theme of training 5-8 grades schoolchildren for subject olympiads in mathematics.

Situation 2. Being a budding teacher, you were asked to prepare a report for the methodic seminar regarding the issue of organization of lyceum students for participation in research projects competition. 
Situation 3. Under conditions of informatization of education issues of efficient application of informationcommunication technologies in the organization of educational work with students become actual. Being a teacher of computer science, you were asked to prepare a report for methodic seminar devoted to innovative forms of educational activities involving the application of information-communication technologies.

Situation 4. You teach mathematics in the 10th grade and at the beginning of an academic year you faced the problem: how to improve students training for the Unified State Examination in mathematics? Administration of the lyceum asked you to speak at the methodic seminar regarding the issue of application of informationcommunication technologies in the process of organization of additional courses for graduates' preparation for the exam.

Criteria for assessment of self-organization and self-control competence are the following. For the component R1: 1) the ability to formulate the issue of the research is demonstrated; 2) the ability to set the goal of the scientificresearch activity is demonstrated; 3 ) the ability for expressive representation of the statement (thesis) of the research is demonstrated. For the component R2: 1) the ability to formulate the issue of future research is demonstrated; 2 ) the ability to indicate the main idea (purpose) of research is demonstrated; 3 ) the ability to set goals of research is demonstrated. For the component R3: 1) the ability to perform informational analysis of pedagogical process (notion) is demonstrated; 2 ) the ability to process information flows during the set issue studying is demonstrated; 3) the ability to represent possible forms of project implementation in educational institutions is demonstrated. Assessment is made by the three-point scale. Each $r$ vector component is within the range from 0 up to 6 .

Methodic orientation supposes possession of such skills as goal-setting, projection, planning, realization, diagnostics of education process and correction of education results. Goal-setting consists of the preliminary understanding of possible results of the impact of educational content, the rhythm of courses and teacher actions aimed at the personal development of a student. Projection, as the ability to technologize the educational process (determine main components of content and types of activity for its perception; to estimate time and define control points), connected with the planning of activity results. Project realization depends not only on theoretical knowledge but also on organizational, communicative, psychological capacity and developed diagnostic skills of a teacher. Diagnostics of the educational process is based on detection of reasons of a student falling behind and predicting the achieved results. Not only personality and activity of a student are subject to diagnostics, but also actions of a teacher, that allow reviewing goals and correct educational process if required.

An important role in mathematics teacher methodic training is played by system-activity-based competence, for diagnostics of which the following criteria are used. For the component M1: 1) ability to set goals, plan and develop educational mathematical activity is demonstrated; 2 ) understanding of methods and teaching techniques, verbal specific features of mathematical constructions is demonstrated. For the component M2: 1) ability to develop goals of education, to plan classes and perform diagnostics of the results of students' educational activity is demonstrated; 3) ability to perform analysis of didactic materials, educational and additional literature is demonstrated. For the component M3: 1) readiness to select efficient forms and methodic components of education is demonstrated; 2) ability for self-assessment of the experience of educational process organization and for understanding its impact on student's personality is demonstrated. Assessment is made by three-point scale, based on the results of representation of methodic part of professional situations in terms of project activity and, correspondingly, each $\mathbf{m}$ vector component (M1, M2, M3) is within the range from 0 up to 4 .

\section{Second Stage Description}

At the 2nd stage, we tested developed educational-methodic materials, examined the efficiency of organizational forms (individual and group) for practical classes and exam holding. Let us provide a short description of the organization of exam in the discipline "Informatization of education", which was held in the form of a creative report on the results of the implementation of methodic projects by senior students. For projects implementation, students were divided into small groups (2-3 students) and a month before the exam each group received the text of pedagogical situation on the issues of organization of mathematical education at school. During the exam student should demonstrate: 1) knowledge of content and structure of pedagogical activity of a teacher during the organization of mathematical education at school; 2) ability to analyze information-educational resources; prepare for classes with the application of information resources; prepare educational-program, methodic documentation, and complexes of didactic teaching techniques for their adaptation under real conditions of the educational process. At the kickoff class, before methodic project execution, students studied matrix of assessment in accordance with criteria for $\mathbf{r}(\mathrm{R} 1, \mathrm{R} 2, \mathrm{R} 3)$ and $\mathbf{m}$ (M1, M2, M3) vectors components.

Future teachers prepared methodic projects in written form and presented them to the group, answering questions of their opponents. Quality of speech and presentation is under vector $\mathbf{p}$ (P1, P2, P3), components of which are assessed by the following criteria. For the component P1 - knowledge of the material and public speaking of speakers: 0 points - poor knowledge of the material, project is presented by reading the text; 1 point - partial 
reading of the text, interaction with the audience; 2 points - good knowledge of the material, active interaction with the audience. For the component P2 - concordance of text with the presentation: 0 points - information provided in slides does not solve the set issue; 1 point - information provided in slides is mainly textual; 2 points -- information provided in slides solves the set issue, it contains schemes, diagrams, and other visual material. For the component P3 - creativity of speakers' presentations, uniform distribution of material between members of the small group: 0 points - author's position is not provided in presentation; 1 point - unequal contribution of group members to preparation and presentation of the project; 2 points - all group members are involved into work, presentation is argumented and clear.

Preparation of methodic projects and presentation of them by students at the exam is assessed not only by the teacher but by all present students. It should be noted that future teachers take an active part in peer assessment and this promotes the development of their methodic competency. At the end of the exam we carry out reflection students are proposed to anonymously answer the following questions:

1. Please, assess the process of holding the exam in the form of a creative report.

2. What difficulties did you experience in the process of methodic project preparation?

3. Did you learn something new from reports of your colleagues?

4. Please, define advantages of project work.

5. Your comments and recommendations in relation to the organization of exam involving preparation and presentation of methodic project

Holding exam in such a form was highly assessed by students. Reflection results showed that future teachers are fond of the process of active search because their involvement into collective profession oriented activity stimulates the development of creative thinking, skills of research activity, public speaking and ability to work in a team.

\section{RESULTS}

Vector modeling studies efficiency of future mathematics teacher methodic training. The result of the above mentioned and described 1st stage is the determination of the set of competencies, realized during future mathematics teacher training. Vector $\mathrm{c}(\mathrm{C} 1, \mathrm{C} 2, \mathrm{C} 3)$ contains information-methodic competence required for representation of information worldview: it includes knowledge about sources of information, ways of its representation, transformation and application, ability to work with information of different types and content. Social interaction competence is defined by vector s (S1, S2, S3). This competence includes mastery of speech as the instrument for constructive communication; skills of establishment and maintenance of contacts; active listening and initiative, exchange of social and personal experience, feelings and moods. Vector o (O1, O2, O3) shows possession by a future teacher of individual cognitive activity competence. The competence includes: cognitive (determination and assessment of contradiction; detection of the general in the particular, analysis of the particular from the point of view of the general; formulation of the goal defined in the issue); creative (self-sufficiency in search and analysis of rational ways of task solution; readiness to solve complex issues and accept non-standard issue solutions; critical thinking); organization-activity-based (setting goal and organization of its achievement; understanding the methods of scientific-research work; adequate representation of final result and making conclusions based o the carried out research). Competence of self-organization and self-control is presented by vector $\mathrm{r}(\mathrm{R} 1, \mathrm{R} 2, \mathrm{R} 3)$. Based on objective self-assessment and reflection, competence is responsible for: orientation in the personal inner world (psychic and physical states, demands and requests); adequate self-determination and goal-setting under conditions of the excessive degree of uncertainty and risk; abilities for critical thinking and formulation of critical statements. System-activity-based competence is characterized by vector m (M1, M2, M3), components of which are widely represented in the organization of mathematics teacher methodic training. It includes the following capabilities: to plan and predict; to project and model; to apply knowledge for solving new issues; to apply knowledge in practice; to carry out research activity.

The result of the 1st stage is testing of educational and methodic materials focused on the development of competencies of future mathematics teachers. Performance by them of practice-oriented tasks was assessed following the criteria for diagnostics of information-methodic and social interaction competencies, which correspond to cognitive (vector $\mathbf{s}$ ) and social-humanitarian (vector $\mathbf{c}$ ) orientations of the model of student methodic training. Competence of individual cognitive activity, corresponding to vector $\mathbf{o}$, is assessed on the basis of the results of execution of text story tasks, oriented to studying of full effect model. Description of the first stage contains detailed description of the procedure for diagnostics performance for each component of competencies. Results of tasks execution by students are provided by resulting vector $\mathbf{w}\left(w_{1} ; w_{2} ; w_{3}\right)$, components of which $w_{1}=$ $\mathrm{S} 1+\mathrm{C} 1+\mathrm{O} 1, w_{2}=\mathrm{S} 2+\mathrm{C} 2+\mathrm{O} 2, w_{3}=\mathrm{S} 3+\mathrm{C} 3+\mathrm{O} 3$ characterize cognitive, socio-humanitarian and operationalactivity orientations. 
The result of the 2nd stage is argumentation of the efficiency of vector modeling in terms of students' methodic training results diagnostics. Various organizational forms were used for holding practical classes and exam. In order to develop skills of teamwork, it is reasonable to use group form of project activity. Each group, consisting of 2-3 students, was provided pedagogical situations for further consideration. Situations were described at the 1st stage of research.

Another issue of no small importance for future mathematics teacher is to present the prepared methodic project. Project activity is focused on the development of self-organization and self-control (vector $\mathbf{r}$ ) and systemactivity (vector $\mathbf{m}$ ) competencies. Criteria for competencies assessment are provided in the description of the 1st stage of research.

For a future teacher, it is very important to provide a good presentation for his report. For diagnostics of such ability was introduced vector $\mathbf{p}$ (P1, P2, P3), components of which are assessed by definite criteria stated in the description of the 2nd stage of research. Optimal representation of the results of preparation and presentation by students of their methodic projects is provided by vector $\mathbf{v}\left(v_{1}, v_{2}, v_{3}\right)$, which is the sum of vectors $\mathbf{r}, \mathbf{m}$ and $\mathbf{p}$. Consequently, $v_{1}=\mathrm{R} 1+\mathrm{M} 1+\mathrm{P} 1, v_{2}=\mathrm{R} 2+\mathrm{M} 2+\mathrm{P} 2, v_{3}=\mathrm{R} 3+\mathrm{M} 3+\mathrm{P} 3$. Resulting vectors $\mathrm{v}$ and $\mathrm{w}$ show "intensity" and "orientation" of students methodic training. Components of vectors $\mathrm{v}$ and $\mathrm{w}$ are within the range from 0 up to 12.

Developed by us methodology for vector modeling (Dorofeev \& Latypova, 2014, 2015) shows that vector module characterizes "intensity" and directional cosines - "orientation" in relation to coordinate axes. Results of work of each student during execution of practice-oriented tasks at practical classes and methodic projects at the exam (i.e. components of all vectors $\mathbf{r}, \mathbf{m}, \mathbf{p}$ and $\mathbf{s}, \mathbf{c}, \mathbf{o}$ ) should be provided in the form of a table for further calculation of average values of vector components for each student and the whole group. Modules are calculated $|\mathbf{v}|=\sqrt{v_{1}^{2}+v_{2}^{2}+v_{3}^{2}},|\mathbf{w}|=\sqrt{w_{1}^{2}+w_{2}^{2}+w_{3}^{2}}$ and directional cosines are calculated $\left(\Omega\left(v_{\mathrm{n}}\right)=v_{\mathrm{n}} /|\mathbf{v}|, \Omega\left(w_{\mathrm{n}}\right)=w_{\mathrm{n}} /|\mathbf{w}|\right.$, $\mathrm{n}=1,2,3)$.

Table 1 contains average numeric values of resulting vectors $\mathrm{v}$ and $\mathrm{w}$ components for the group, consisting of 20 students:

Table 1. Average numeric values of resulting vectors $v$ and $w$ components

\begin{tabular}{cccccccccccccc}
\hline & $\mathbf{v}$ & \multicolumn{3}{c}{ Module } & \multicolumn{2}{c}{ Directional cosines } & \multicolumn{2}{c}{ W } & \multicolumn{2}{c}{ Module } & \multicolumn{2}{c}{ Directional cosines } \\
\hline$v_{1}$ & $v_{2}$ & $v_{3}$ & $|\mathbf{v}|$ & $\Omega\left(v_{1}\right)$ & $\Omega\left(v_{2}\right)$ & $\Omega\left(v_{3}\right)$ & $w_{1}$ & $w_{2}$ & $w_{3}$ & $|\mathbf{w}|$ & $\Omega\left(w_{1}\right)$ & $\Omega\left(w_{2}\right)$ & $\Omega\left(w_{3}\right)$ \\
\hline 10.3 & 9.8 & 10.1 & 17.4 & 0.59 & 0.56 & 0.58 & 9.5 & 8.6 & 9.1 & 15.7 & 0.61 & 0.55 & 0.58 \\
\hline
\end{tabular}

Values of vectors components are within the range of [0:12], that is why the maximum value of vectors $\mathrm{v}$ and $\mathrm{w}$ module is 20.8. The greater the value of the absolute characteristic, the better results of future mathematics teacher methodic training. Directional cosines are required for analysis of vectors orientation in relation to components: the first component part characterizes cognitive, the second - activity, the third - value-based feature of competencies. Relative values satisfy the following identities: $\sum_{n=1}^{3} \Omega^{2}\left(v_{n}\right)=1, \sum_{n=1}^{3} \Omega^{2}\left(w_{n}\right)=1$. That is why when they close to $\frac{1}{\sqrt{3}}$ (i.e. take the value 0.58 ), the optimal level of methodic training can be established. This means that vector is oriented in relation to all component parts and, consequently, cognitive, activity and value-based components are equally presented in the developed competencies. In case any two of relative characteristics are minimized, the corresponding vector is oriented along the third component part and, consequently, competencies are poorly developed. When one of the relative characteristics is minimized, the vector is oriented along the rest two components, that indicates the medium level of competencies development.

On the basis of results, provided in the table, we can make conclusions about absolute and relative characteristics of resulting vectors: 1) $|\mathbf{v}|=17.4,|\mathbf{w}|=15.7$, i.e. their values differ from maximum by not more than $24 \%$, so competencies of students are developed up to sufficient level; 2 ) relative characteristics of v vector are close to 0.58 and this means that developed competencies (information-methodic, social interaction, individual cognitive activity) contain equal parts of cognitive, activity and value-based components; 3 ) one of the relative characteristics of $\mathrm{w}$ vector is minimized, that means the medium level of competencies manifestation.

The presented vector modeling helps to provide the individual profile for each student. And on the basis of average values if vectors components it is possible to diagnose results of methodic training of the whole group.

\section{DISCUSSIONS}

The proposed vector modeling for methodic training diagnostics, as well as any other modeling, should not be absolutized. The main advantage of this method is the possibility to perform multi-aspect analysis for professional becoming of a maths teacher. Of course, expert assessments are in some degree conventional, but they provide a good basis for reflexive analysis by each teacher of the prospects of academic discipline for students' competencies development. 
Carrying out of the research showed a new issue - lack of experience of students for holding exam in the form of a creative report on the results of preparation of group projects. Some students noted in their questionnaires that they feel lack of teamwork experience. This is also obvious due to low values of $w$ vector components, that orients teacher to pay more attention to operational-activity and socio-humanitarian orientations of mathematical training. For this purpose, we plan tasks aimed at the development of teamwork skills and also to hold consultations devoted to the issue of studying by future teachers of full effect model. Control of cognitive activity in the full effect model is directly connected with the creative-innovation activity of a future teacher which includes: a) cognitive visualization of knowledge (data collection, knowledge transfer, making and testing hypotheses, reflection); b) educational activity modeling; c) visual-graphic associations; d) profession oriented tasks and pedagogical situations focused on the development of scientific-research activity techniques.

Practical orientation of a student methodic training is improved when themes of possible projects are determined based on certain demands of educational institutions. Preparing methodic projects, future teachers for several months interact with potential consumers - administrations of educational institutions, under the instruction of which they carry out this research. They develop the most efficient and possible ways of realization of their ideas in the educational practice, carry out experimental work at schools. In such a way, methodic projects could be then further developed in their graduation papers and will possess high practical orientation. In future, we plan to apply such form of the exam in other disciplines of objective and psychological-pedagogical training of future teachers.

\section{CONCLUSION}

We explored essential characteristics of mathematics teacher methodic training by means of detecting cognitive, socio-humanitarian, operational-activity, research and methodic orientations. We developed vector model for mathematics teacher methodic training, vectors of which characterize such competencies as information-methodic, social interaction, individual cognitive activity, self-organization and self-control, and system-activity.

Diagnostics of competencies is performed by vector modeling on the basis of execution of practice-oriented tasks, stimulating motivation of a student to gain methodic knowledge and activity experience, which are of high importance for further professional becoming. Vector modeling provides the qualitative and quantitative assessment of the level of competencies development by means of absolute (i.e. vector module) and relative (i.e. directional cosines) characteristics. Absolute values allow assessing the intensity of methodic training in terms of competencies development, and relative - show the manifestation of cognitive, activity or value-based component parts of competencies. Results of vector modeling are important both for teacher and for a student. On the basis of the real state, a teacher could correct educational process, paying more attention to cognitive, activity or value components of the developed competencies. Qualitative filling of vectors is used in grade-rating systems of students' educational achievement assessment. This stimulates future teachers to acquire professionally important knowledge and types of activity. Results of practice-oriented tasks and methodic projects preparation could be provided in the student's portfolio and characterize the level of his methodic competencies.

The proposed method is suitable for complex diagnostics of professional education results if each module of disciplines possesses diagnostic means developed in accordance with the component composition of the developed competencies. Vector modeling could be used in the process of developing individual educational trajectory of a student. If future teacher studies disciplines of variation modules of the educational program and gains the corresponding competencies, these results could be represented by vectors and individual profile of his professional training could be obtained. Presentation of the results in accordance with the component composition of the developed competencies will allow providing more reliable final certification of student's professional training.

\section{ACKNOWLEDGEMENT}

1. The work is performed according to the Russian Government Program of Competitive Growth of Kazan Federal University.

2. The publication has been prepared with the support of the "RUDN University Program 5-100".

\section{REFERENCES}

Asadullin, R. M., Teregulov, F. S., Koletvinova, N. D., \& Egamberdieva, N. M. (2016). Fundamental and applied education - a new look. IEJME. Mathematics education, 11(1), 23-33. https:/ / doi.org/10.12973/iser.2016.2103a

Asadullin, R. M., \& Vasil'yev, V. I. (2012). Principles of constructing individual educational trajectories based on self-organization of students. Pedagogical Journal of Bashkortostan, 5(42), 59-66. 
Borisenkov, V. P., Gukalenko, O.V., \& Rozov, N. Kh. (2016). Reform of teacher education and teacher development system. Bulletin of Moscow University. Series 20: Pedagogical Education, 1, 3-6.

Borovskikh, A. V., \& Rozov, N. Kh. (2010). Activity principles and pedagogical logic. Pedagogy, 8, 10-19.

Chang, Y. L. (2015). Examining Relationships among Elementary Mathematics Teacher Efficacy and Their Students' Mathematics Self-efficacy and Achievement. EURASIA Journal of Mathematics, Science and Technology Education, 11(6), 1307-1320. https:/ / doi.org/10.12973/eurasia.2015.1387a

Dorofeev, A. V., \& Latypova, A. F. (2014). Multidimensional diagnostics of the competence-oriented mathematical education at university. Bulletin of Bashkir University, 19(1), 253-258.

Dorofeev, A. V., \& Latypova, A. F. (2015). The Vector Model of Competence Diagnostics. Mediterranean Journal of Social Sciences, 6(4), 11-21. https:// doi.org/10.5901/mjss.2015.v6n4s4p

Dorofeev, A. V., \& Piadina, J. V. (2014). Design of multi-dimensional mathematical training. European Journal of Natural History, 3, 13-15.

Dorofeev, A. V., \& Arslanova, M. N. (2017). The principle of multidimensionality in the design of the nonlinear educational process of the future teacher. Pedagogical Journal of Bashkortostan, 3(70), 57-63. https:/ / doi.org/10.21510/1817-3292-2017-3-57-63

Gok, T. (2014). Students' Achievement, Skill and Confidence in Using Stepwise Problem-Solving Strategies. EURASIA Journal of Mathematics, Science and Technology Education, 10(6), 617-624. https:/ / doi.org/10.12973/eurasia.2014.1223a

Gross, J., Robitzsch, A., \& George, A. C. (2016). Cognitive diagnosis models for baseline testing of educational standards in math. Journal of Applied Statistics, 43, 229-243. https:/ / doi.org/10.1080/02664763.2014.1000841

Karaseva, L. M., \& Dorofeev, A. V. (2015). Cluster Model of Formation Multidimensional Information Competence of Student. Eastern European Scientific Journal, 3, 134-137. https:/ / doi.org/10.12851/EESJ201501C04ART0

Khutorskoy, A. V. (2002). Core competencies and educational standards. Internet-journal "Eidos". Retrieved from http:/ / www.eidos.ru/journal/2002/0423-1.htm

Kirikovich, T. E. (2014). The humanistic bases axiological the directed, nonlinear personal didactic model of selftraining. Modern problems of science and education, 1. http:/ / science-education.ru/ru/article/view?id=12068

Kiseleva, O. M., Timofeeva, N. M., \& Bykov, A. A. (2013). The formalization of elements of the educational process on the basis of mathematical methods. Modern problems of science and education, 1, 224-132. http://scienceeducation.ru/107-8283

Kolokolnikova, Z. U., Zakharova, T. V., Yakovleva, E. N., Lobanova, O. B., Korshunova, V. V., \& Farhutdinova, T. G. (2015). The development of universal competencies of a future teacher in educational and extracurricular activities. Modern problems of science and education, 3. http:/ / science-education.ru/ru/article/view?id=23811

Latypova, A. F., \& Dorofeev, A.V. (2016). Point-rating system as a means of implementing the vector model of multidimensional diagnostic results of learning. Modern problems of science and education, 4, 156-162. http:/ / science-education.ru/ru/article/view?id=24937

Li, J., \& Shieh Ch. J. (2016). A Study on the Effects of Multiple Goal Orientation on Learning Motivation and Learning Behaviors. EURASIA Journal of Mathematics, Science and Technology Education, 12(1), 161-172. https://doi.org/10.12973/eurasia.2016.1221a

Liu, O. L., Wilson, M., \& Paek, I. (2008). A Multidimensional Rasch Analysis of Gender Differences in PISA Mathematics. Journal of applied measurement, 9(1), 18-35. http:/ / ncbi.nlm.nih.gov/pubmed/18180547

Naziev, A. Kh. (2000). Humanitarization of the foundations of special training for mathematics teachers in pedagogical universities (PhD Thesis). Moscow: Moscow Pedagogical State University.

Nurullin, R. A. (2013). Philosophic Problems of Correlation between Professional Education and Education in General. Middle-East Journal of Scientific Research, 17(2), 226-232. https:/ / doi.org/10.5829/idosi.mejsr.2013. 17.02.12186

Nurullin, R. A. (2014). Personality Formation and Education in Multicultural Field of Social Life. Middle-East Journal of Scientific Research, 21(1), 38-42. https:/ / doi.org/10.5829/idosi.mejsr.2014.21.01.21174

Ostapenko, A. A. (2007). Modelling of Multidimensional Pedagogical Reality: Theory and Technology. Moscow: Public Education.

Pino-Fan, L. R., Assis, A., \& Castro, W. F. (2015). Towards a Methodology for the Characterization of Teachers' Didactic-Mathematical Knowledge. EURASIA Journal of Mathematics, Science and Technology Education, 11(6), 1429-1456. https:/ / doi.org/10.12973/eurasia.2015.1403a

Shteinberg, V. E. (2002). Multidimensional Didactic Instruments: Theory, Methods, Practice. Moscow: Public Education. 
Shteinberg, V. E. (2015). Theory and practice of didactic multidimensional technology. Moscow: Public Education.

Tchoshanov, M. A. (2011). Engineering of teaching technologies. Moscow, BINOM.

Tchoshanov, M., Lesser, L., \& Salazar, J. (2008). Teacher knowledge and student achievement: Revealing patterns. Journal of Mathematics Education Leadership, 13, 39-49.

Tkachenko, E. V., Shteinberg, V. E., \& Manko, N. N. (2016). Didactic design - 'tools”' approach. Pedagogical Journal of Bashkortostan, 1(62), 51-66.

Yalalov, F. G., \& Kaiumova, L. R. (2015). Psychological Bases of Professional Multidimensionality. The Social Sciences, 10(6), 883-887. https:/ / doi.org/10.3923/sscience.2015.883.887

\section{http://www.ejmste.com}

